\title{
Application of argon plasma sheet in the etching process of calcium carbonate crystals for AFM tests
}

\author{
Magdalena MoczaŁA ${ }^{1}$, Miriam Karpińska ${ }^{2}$, Monika Poznar $^{3}$, Piotr Dobryszycki ${ }^{3}$, \\ ANDRZEJ SIKORA ${ }^{1, *}$ \\ ${ }^{1}$ Electrotechnical Institute, Division of Electrotechnology and Materials Science, \\ M. Skłodowskiej-Curie 55/61, 50-369 Wrocław, Poland \\ ${ }^{2}$ Active Students Association, Association of Polish Electrical Engineers SEP (Branch No. 1 in Wrocław), \\ M. Skłodowskiej-Curie 55/61, 50-369 Wrocław, Poland \\ ${ }^{3}$ Wrocław University of Science and Technology, Faculty of Chemistry, Department of Biochemistry, \\ Wybrzeże Wyspiańskiego 27, 50-370 Wrocław, Poland
}

\begin{abstract}
This paper presents utilization of argon plasma for gradual etching of calcium carbonate crystals. The plasma treatment has been chosen as it appears to be the technique that enables removal of following material layers, thus, the access to the inside of crystals is possible. Examples of investigations of the morphology and mechanical properties of surfaces of calcium carbonate crystals are presented. The impact of plasma treatment has been verified in terms of roughness and volume changes investigated using atomic force microscopy technique in a multi-step experiment. Therefore, we were able to observe the crystal degradation process, revealing the spatial inhomogeneity of the calcium carbonate crystals resulting from their core-shell structure.
\end{abstract}

Keywords: atomic force microscopy; calcium carbonate crystals; microwave plasma; plasma sheet

\section{Introduction}

Biominerals such as bones, teeth, shells and otoliths are composites of calcium carbonate or calcium phosphate and organic matrix. They differ significantly from their inorganic counterparts. Organic matrix, which represents from $0.02 \%$ to $20 \%$ of dry weight, determines the size, shape, polymorph, hierarchical structure and mechanical properties of the composite [1-3]. It is still not fully understood how living organisms incorporate the biological material into crystals to design structures of desired properties.

Otolith matrix macromolecule - 64 (OMM-64) was found in the inner ear of rainbow trout [4]. It is involved in mineralization of otolith, which is a calcium carbonate crystal responsible for gravity sensing. This protein influences the shape and polymorph of the crystal but its effect on the internal structure and mechanical properties is still not

*E-mail: sikora@iel.wroc.pl recognized [5]. In this study, a recombinant protein was used to produce calcium carbonate crystals $\left(\mathrm{CaCO}_{3}\right)$ in vitro.

The effect of matrix proteins on crystal formation, structure and properties is extensively investigated to provide more insight into biomineralization process and its pathology [6-8]. Moreover, it gives guidelines on how to mimic a nature and design artificial materials of specific properties [9]. Especially promising seem to be the techniques that allow us to look deep inside the crystals. A good candidate for that appears to be a plasma sheet $[10,11]$.

Investigations of the influence of plasma treatment on calcium carbonate have been performed using scanning calorimetry, tensile tests and dynamic mechanical analysis [12]. The analysis of variations of decomposition and attrition rates of calcite with plasma operating conditions were also investigated [13]. Recently, the surface treatment using discharge plasma for commercially available $\mathrm{CaCO}_{3}$ nanoparticles was used for investigation 
of filler particle activation, and appearance of agglomerates was observed using scanning electron microscopy [14].

Atomic force microscopy (AFM) has been used with success in investigations of the influence of a particular medium on specific materials in order to obtain information about structure, resistance or homogeneity $[15,16]$. AFM technique is particularly useful when samples are of micrometer size, and/or the changes that need to be recorded are in nanometer range, which excludes the use of macroscopic methods [17].

In this work, we proposed an investigation of morphology and surface mechanical properties of $\mathrm{CaCO}_{3}$ crystals treated by plasma sheet using AFM. The impact of the plasma treatment was verified in terms of roughness changes while the aim of this process was exposing deeper layers of the crystals. Investigated $\mathrm{CaCO}_{3}$ crystals exposed to plasma were gradually etched, allowing to carry out measurements of morphological and mechanical properties of their inner areas. This opened a possibility of investigation of their entire structure and understanding the properties which determine their functioning in the natural environment. According to our knowledge, such an approach has not been reported so far.

\section{Materials and methods}

\subsection{In vitro calcium carbonate mineral- ization}

In vitro calcium carbonate mineralization was carried out using modified diffusion method [4], used previously for precipitation of crystals in the presence of Stm and Stm-like proteins [7, 8]. This method is based on decomposition of ammonium hydrocarbonate and slow $\mathrm{CO}_{2}$ diffusion into calcium dichloride solution [18]. Calcium carbonate precipitation in the presence and absence of recombinant otolith matrix macromolecule - 64 (rOMM-64) was carried out for $24 \mathrm{~h}$ in a closed dessicator. $200 \mu \mathrm{l}$ of $10 \mathrm{mM} \mathrm{CaCl}{ }_{2}$ was placed in 96-well plates above $2 \mathrm{mg}$ of solid $\left(\mathrm{NH}_{4}\right)_{2} \mathrm{HCO}_{3}$ covered with Parafilm with 5 holes. A circular cover glass of a $5 \mathrm{~mm}$ diameter was placed on the bottom of each well. Calcium dichloride solution was supplemented with a final concentration of $0 \mu \mathrm{g} / \mathrm{ml}$ and $60 \mu \mathrm{g} / \mathrm{ml}$ rOMM-64, respectively. After $48 \mathrm{~h}$ incubation at room temperature, the crystallization solution was removed, crystals were washed twice with $200 \mu \mathrm{L}$ distilled water and air-dried. Fig. 1 presents optical microscope images of the calcium carbonate crystals.

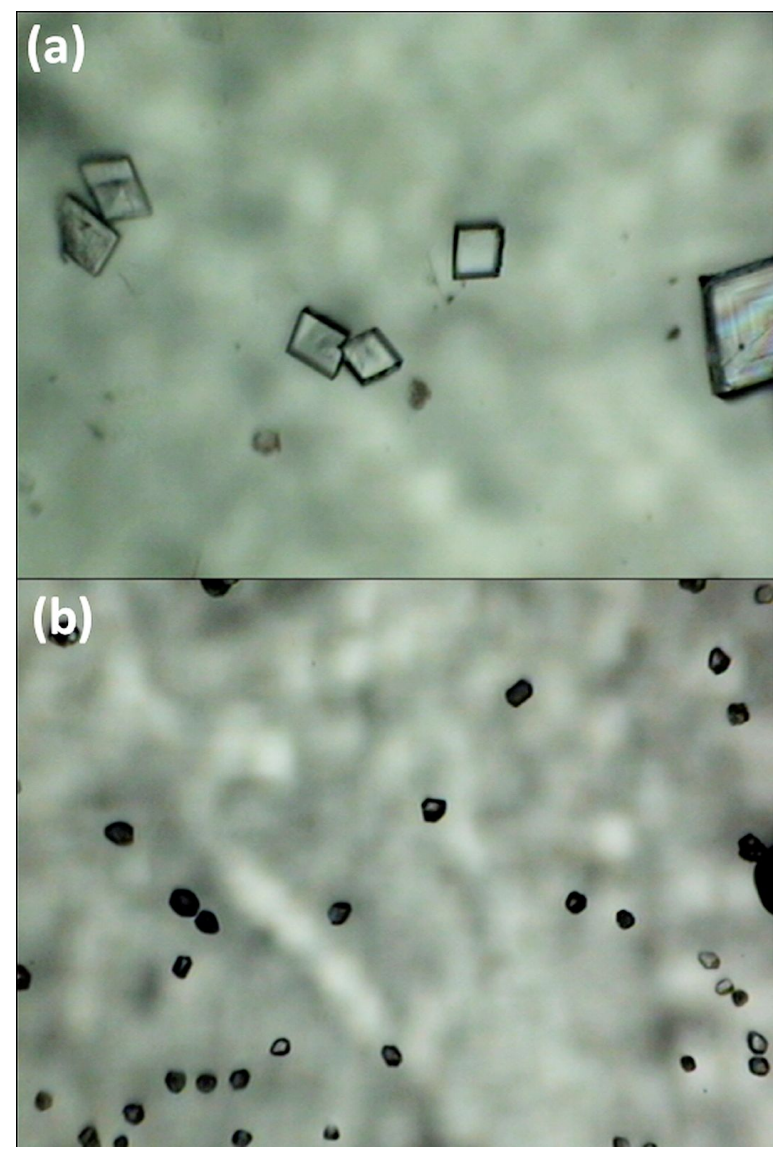

Fig. 1. Example images of (a) pure calcium carbonate crystals and (b) calcium carbonate crystals doped with rOMM-64.

\subsection{Plasma sheet}

For the study, we have used a waveguide-based microwave source for generation of argon plasma sheet at atmospheric pressure [10, 11]. This novel microwave source operated in argon under atmospheric pressure and delivered plasma in the form of a plasma sheet. In this source, the microwave 
power was supplied to the discharge region via a rectangular waveguide. A flat quartz box was inserted into the waveguide through the rectangular slits which were cut in the wider waveguide walls, perpendicularly to the narrow walls. The microwave discharge was generated inside the flat quartz box and extended beyond the box. Additionally, a movable table for specimens allowed for tuning the time of plasma treatment procedure. Fig. 2 presents the waveguide-based microwave source for the generation of Ar plasma sheet. The $\mathrm{CaCO}_{3}$ crystals were treated with plasma microwave power of $1300 \mathrm{~W}$ at Ar flow rate of $20 \mathrm{~L} / \mathrm{min}$, for $1 \mathrm{~s}$ in 20 courses.
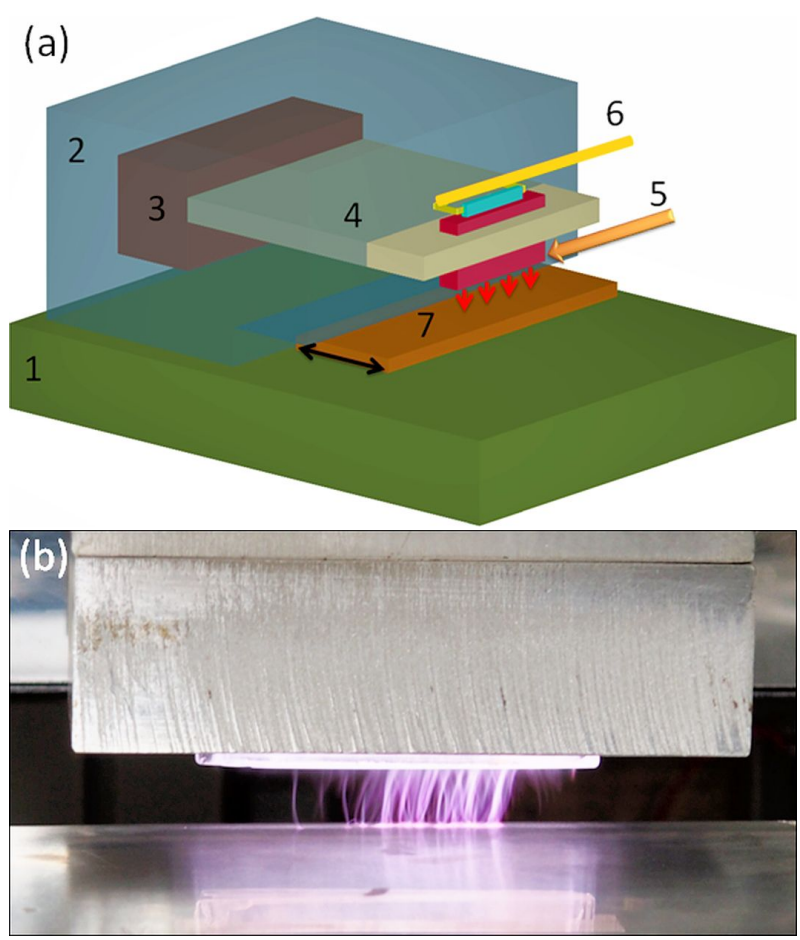

Fig. 2. The waveguide-based microwave source for the generation of Ar plasma sheet (a) the schematic of the device ( 1 - base, 2 - housing, 3 - magnetron, 4 - waveguide, 5 - plasma guide, 6 argon inlets, 7 - sample holder) and (b) the photograph of plasma sheet.

The influence of plasma on $\mathrm{CaCO}_{3}$ crystals topography was investigated using a commercial Innova AFM system from Bruker Company. The measurements were done at ambient conditions using a force modulation and tapping modes.
The whole procedure with plasma treatment and AFM investigation was repeated 3 times. For each step of the experiment, AFM images were recorded for two specific areas on two different crystals. The data were processed using SPIP software from Image Metrology Company and the roughness parameters, including $S_{q}$ (root mean square) and $S_{a}$ (average roughness) were calculated [19]. By observing the impact of the process on specific areas, using precise sample positioning ability in AFM, we could obtain the results with high degree of confidence [20].

\section{Results and discussion}

The $\mathrm{CaCO}_{3}$ crystals are supposed to have a core-shell structure and this may be the reason of inhomogeneous morphology and mechanical properties. Fig. 3 presents the mechanical differences between the steps on the surface recorded using the FMM (force modulation microscopy) technique [21]. One can see the subtle differences in mechanical properties at various steps. This inhomogeneity of mechanical properties may affect the different reaction to the plasma treatment.

The examples of topography measurements are shown in Fig. 4. Images for a sample before and after three individual steps of plasma treatment are shown sequentially. It is observed, that the removal process of the top layer of $\mathrm{CaCO}_{3}$ crystal proceeded in inhomogeneous fashion.

Table 1 and Table 2 show the values of the roughness parameters $S_{a}$ and $S_{q}$ obtained for two specific areas on two different crystals before and after three procedures of plasma treatment. Based on the results of roughness measurements given in the tables, one can observe the changes after each exposure to the plasma. The process is not only connected with removal of material but also with migration of material on the surface. One should remember that plasma also generates high temperature which additionally complicates the analysis of the phenomena occurring on the $\mathrm{CaCO}_{3}$ crystal surface. 
(a)

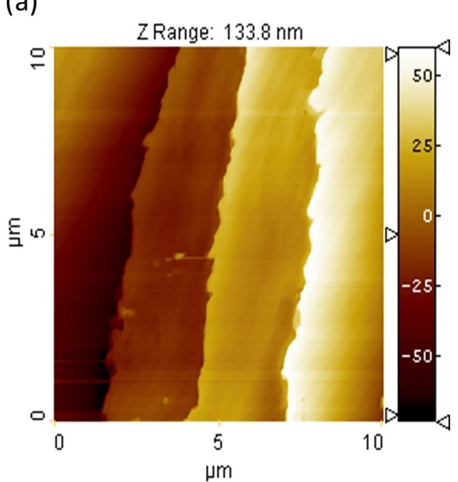

(b)

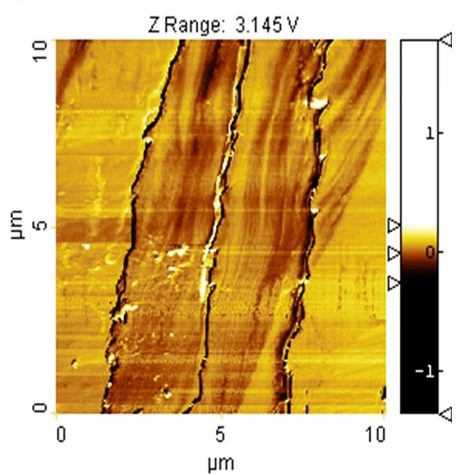

(c)

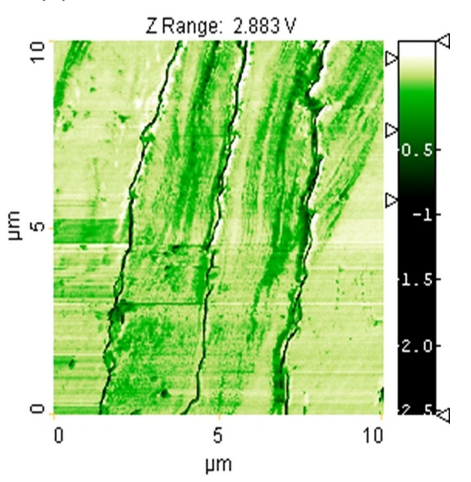

Fig. 3. The images of $\mathrm{CaCO}_{3}$ crystal before the procedure of plasma treatment: (a) topography, (b) FMM amplitude and (c) FFM phase.

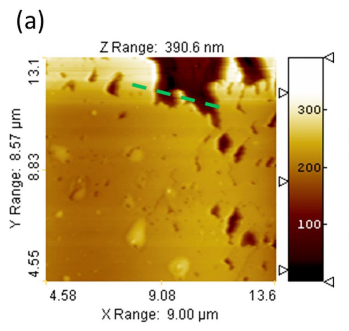

(b)

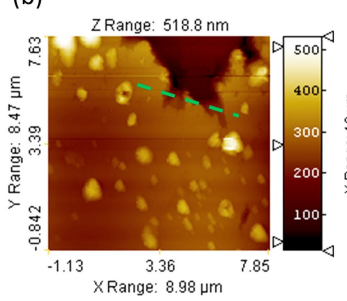

(c)

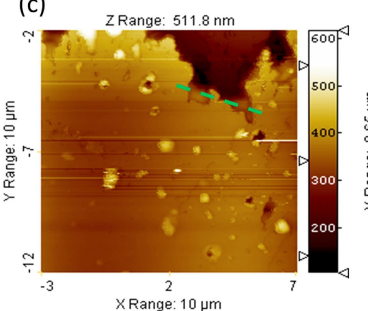

(d)

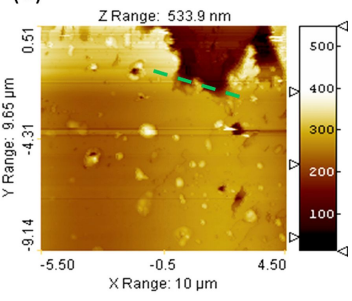

Fig. 4. Examples of topography of a $\mathrm{CaCO}_{3}$ crystal (a) before and after (b) first, (c) second and (d) third procedure of plasma treatment.

Based on the obtained AFM images, the crosssection analysis was performed. The locations of cross-sections are indicated on the AFM images in Fig. 4 with the dashed line. The difference between the cross-section area before and after III plasma treatments are shown in Fig. 5. The material loss in this particular cross-section was calculated as $0.14 \mu^{3}$.

\section{Conclusions}

In this paper, we have presented the preliminary results of utilization of argon plasma in etching of $\mathrm{CaCO}_{3}$ crystals as a method of outer layer removal, in order to access the inner areas and to investigate their morphological and mechanical properties. Promising outcome of the experiments is encouraging to perform further works, as the complexity and small size of the investigated objects strongly limits the range of available investigation methods.

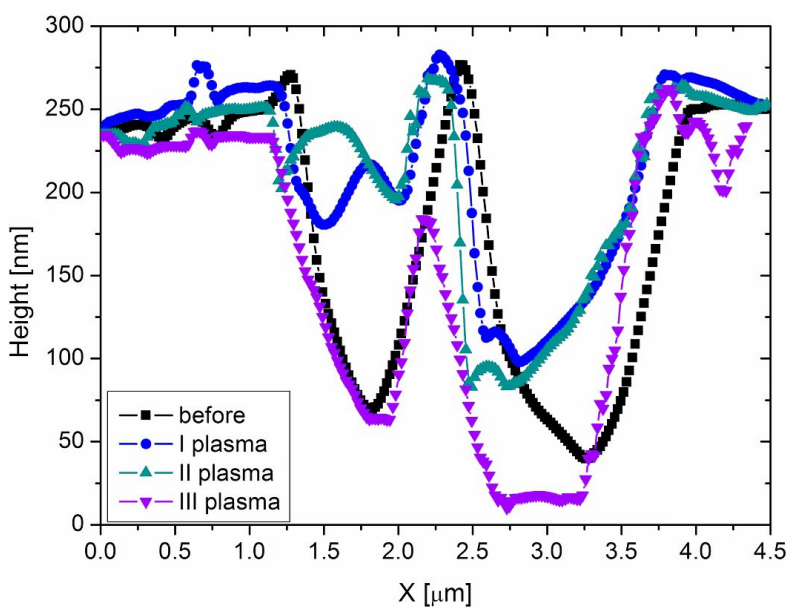

Fig. 5. Cross-section of topography of a $\mathrm{CaCO}_{3}$ crystal before and after 3 steps of plasma treatment.

The removal of material was observed with high degree of confidence, as specific areas were imaged at each step of the etching process. On the basis of AFM investigations, an increase of the cracks 
Table 1. The roughness parameters for crystal 1 .

\begin{tabular}{ccccccccc}
\hline & \multicolumn{2}{c}{ Before } & \multicolumn{2}{c}{ I plasma } & \multicolumn{2}{c}{ II plasma } & \multicolumn{2}{c}{ III plasma } \\
& $\begin{array}{c}\mathrm{S}_{\mathrm{a}} \\
{[\mathrm{nm}]}\end{array}$ & $\begin{array}{c}\mathrm{S}_{\mathrm{q}} \\
{[\mathrm{nm}]}\end{array}$ & $\begin{array}{c}\mathrm{S}_{\mathrm{a}} \\
{[\mathrm{nm}]}\end{array}$ & $\begin{array}{c}\mathrm{S}_{\mathrm{q}} \\
{[\mathrm{nm}]}\end{array}$ & $\begin{array}{c}\mathrm{S}_{\mathrm{a}} \\
{[\mathrm{nm}]}\end{array}$ & $\begin{array}{c}\mathrm{S}_{\mathrm{q}} \\
{[\mathrm{nm}]}\end{array}$ & $\begin{array}{c}\mathrm{S}_{\mathrm{a}} \\
{[\mathrm{nm}]}\end{array}$ & $\begin{array}{c}\mathrm{S}_{\mathrm{q}} \\
{[\mathrm{nm}]}\end{array}$ \\
\hline \hline area 1 & 204.76 & 209.17 & 242.69 & 249.94 & 336.71 & 340.75 & 248.66 & 253.70 \\
area 2 & 160.73 & 173.06 & 176.63 & 190.36 & 232.88 & 242.62 & 258.38 & 263.59 \\
\hline
\end{tabular}

Table 2. The roughness parameters for crystal 2.

\begin{tabular}{ccccccc}
\hline & \multicolumn{2}{c}{ Before } & \multicolumn{2}{c}{ II plasma } & \multicolumn{2}{c}{ III plasma } \\
& $\mathrm{S}_{\mathrm{a}}$ & $\mathrm{S}_{\mathrm{q}}$ & $\mathrm{S}_{\mathrm{a}}$ & $\mathrm{S}_{\mathrm{q}}$ & $\mathrm{S}_{\mathrm{a}}$ & $\mathrm{S}_{\mathrm{q}}$ \\
{$[\mathrm{nm}]$} & {$[\mathrm{nm}]$} & {$[\mathrm{nm}]$} & {$[\mathrm{nm}]$} & {$[\mathrm{nm}]$} & {$[\mathrm{nm}]$} \\
\hline \hline area 1 & 186.72 & 187.18 & 167.88 & 168.62 & 243.69 & 244.29 \\
area 2 & 62.39 & 62.58 & 26.27 & 26.41 & 20.65 & 20.79 \\
\hline
\end{tabular}

and gaps on the $\mathrm{CaCO}_{3}$ crystals surfaces may be noticed. The accumulation of material on the surface is also visible. This is related to the process of removing the top layer of $\mathrm{CaCO}_{3}$ crystal which is inhomogeneous.

Further optimization of the etching process parameters is planned as a certain outcome quality is expected in terms of intended experiments. By enabling this processing method one should obtain the access to quasi tomography approach. In addition, the application of this approach will be tested for other materials and structures, such nanocomposites or tissue.

\section{Acknowledgements}

This work was partially supported by a statutory activity subsidy from the Polish Ministry of Science and Higher Education for the Electrotechnical Institute, statutory activity subsidy from the Polish Ministry of Science and Higher Education for the Faculty of Chemistry of the Wroclaw University of Science and Technology, the National Science Centre (Grant Number UMO-2015/19/B/ST10/02148) and the National Science Centre (Grant Number DEC-2015/19/B/ST8/02123).

\section{References}

[1] Gower L.B., Chem Rev., 108 (2008), 4551.

[2] Feng Q., Prog. Mol. Subcell Biol., 52 (2011) 141.

[3] Gajueraman S., Narayanan K., Hao J., Qin C., George A., J. Biol. Chem., 282 (2007), 1193.

[4] Tohse H., Takagi Y., Nagasawa H., FEBS J., 275 (2008), 2512.

[5] Tohse H., Saruwatari K., Kogure T., NagaSawa H., Takagi Y., Cryst. Growth Des., 9 (2009), 4897.

[6] Kawasaki K., Buchanan A.V., Weiss K.M., Annu. Rev. Genet., 43 (2009), 119.
[7] RÓżyCKA M., WOJTAS M., JAKÓB M., Stigloher C., GrzeszKowiak M., MAZUr M., OŻYhar A., PLoS One, 9 (2014), e114308.

[8] Wojtas M., Wolcyrz M., Ożyhar A., DoBRYSZYCKI P., Cryst. Growth Des., 12 (2012), 158.

[9] Thula T.T., Rodriguez D.E., LeE M.H., Pendi L., Podschun J., Gower L.B., Acta Biomater., 8 (2011) 3158.

[10] Jasiński M., Goch M., Mizeraczyk J., Przeglad Elektrotechniczny, 86 (2010), 112.

[11] Jasiński M., Mizeraczyk J., IEEE Trans. Plasma Sci., 39 (2011), 2136.

[12] Akovali G., Akman M.A., Polym. Int., 2 (1997), 195.

[13] Flamant G., Chraibi M., Vallbona G., Bertrand C., J. Phys. Colloques, 51 (C5) (1990), C5-27.

[14] KrC̆ma F., Kalina L., Nezbedová E., Pospíšsil L., Dombková J., LaCh R., Grellmann, W., RFP, 11 (2016), 52.

[15] Bussiere P.O., Desnoux E., Collin S., Vial C., Therias S., Gardette J.L., Polym. Degrad. Stab., 128 (2015), 200.

[16] Lochyński P., Sikora A., Szczygię B., Surf. Eng., 33 (5) (2017), 395.

[17] Sikora A., Woszczyna M., Friedemann M., Kalbac M., Ahlers F.-J., Micron, 43 (2012), 479.

[18] Wojtas M., HoŁubowicz R., Poznar M., MaCIEJEWSKA M., OŻYHAR A., DOBRYSZYCKI P., Biochemistry, 54 (2015), 6525.

[19] www.imagemet.com, accessed on: 2017.03.05.

[20] Sikora A., Meas. Sci. Technol., 28 (2017), 034016.

[21] Maivald P., Butt H.J., Gould S.A.C., Prater C.B., Drake B., Gurley J.A., Elings V.B., HANSMA P.K., Nanotechnology, 2 (2) (1991), 103.

Received 2017-03-29 Accepted 2018-02-04 